\title{
A comparison of head dynamic response and brain tissue stress and strain using accident reconstructions for concussion, concussion with persistent postconcussive symptoms, and subdural hematoma
}

\author{
R. Anna Oeur, MSc, ${ }^{1}$ Clara Karton, MSc, ${ }^{1}$ Andrew Post, PhD, ${ }^{1}$ Philippe Rousseau, PhD, ${ }^{1}$ \\ T. Blaine Hoshizaki, PhD, ${ }^{1}$ Shawn Marshall, MD, MSc, ${ }^{2}$ Susan E. Brien, MD, ${ }^{3}$ Aynsley Smith, PhD, ${ }^{4}$ \\ Michael D. Cusimano, MD, PhD, ${ }^{5}$ and Michael D. Gilchrist, PhD, DEng ${ }^{6}$ \\ ${ }^{1}$ School of Human Kinetics, University of Ottawa; ${ }^{2}$ Clinical Epidemiology, Ottawa Hospital Research Institute, Ottawa, Ontario; \\ ${ }^{3}$ Department of Neurosurgery, Centre de Santé et de Services Sociaux (CSSS) Gatineau (Hull site), Quebec, Canada; \\ ${ }^{4}$ Department of Orthopedics and Physical Medicine and Rehabilitation, Mayo Clinic, Rochester, Minnesota; ${ }^{5}$ Injury Prevention \\ Research Office and Division of Neurosurgery, St. Michael's Hospital, and University of Toronto, Ontario, Canada; and ${ }^{6}$ School of \\ Mechanical and Materials Engineering, University College Dublin, Ireland
}

OBJECT Concussions typically resolve within several days, but in a few cases the symptoms last for a month or longer and are termed persistent postconcussive symptoms (PPCS). These persisting symptoms may also be associated with more serious brain trauma similar to subdural hematoma (SDH). The objective of this study was to investigate the head dynamic and brain tissue responses of injury reconstructions resulting in concussion, PPCS, and SDH.

METHODS Reconstruction cases were obtained from sports medicine clinics and hospitals. All subjects received a direct blow to the head resulting in symptoms. Those symptoms that resolved in 9 days or fewer were defined as concussions $(n=3)$. Those with symptoms lasting longer than 18 months were defined as PPCS $(n=3)$, and 3 patients presented with SDHs $(n=3)$. A Hybrid III headform was used in reconstruction to obtain linear and rotational accelerations of the head. These dynamic response data were then input into the University College Dublin Brain Trauma Model to calculate maximum principal strain and von Mises stress. A Kruskal-Wallis test followed by Tukey post hoc tests were used to compare head dynamic and brain tissue responses between injury groups. Statistical significance was set at $p<0.05$.

RESULTS A significant difference was identified for peak resultant linear and rotational acceleration between injury groups. Post hoc analyses revealed the SDH group had higher linear and rotational acceleration responses (316 $\mathrm{g}$ and $23,181 \mathrm{rad} / \mathrm{sec}^{2}$, respectively) than the concussion group (149 $\mathrm{g}$ and $8111 \mathrm{rad} / \mathrm{sec}^{2}$, respectively; $p<0.05$ ). No significant differences were found between groups for either brain tissue measures of maximum principal strain or von Mises stress.

CONCLUSIONS The reconstruction of accidents resulting in a concussion with transient symptoms (low severity) and SDHs revealed a positive relationship between an increase in head dynamic response and the risk for more serious brain injury. This type of relationship was not found for brain tissue stress and strain results derived by finite element analysis. Future research should be undertaken using a larger sample size to confirm these initial findings. Understanding the relationship between the head dynamic and brain tissue response and the nature of the injury provides important information for developing strategies for injury prevention.

http://thejns.org/doi/abs/10.3171/2014.10.JNS14440

KEY WORDS accident reconstruction; traumatic brain injury; concussion; finite element modeling; Hybrid III headform; subdural hematoma; persistent postconcussive symptoms

ABBREVIATIONS MADYMO = Mathematical Dynamic Models; $\mathrm{PPCS}=$ persistent postconcussive symptoms; $\mathrm{SDH}=$ subdural hematoma; $\mathrm{TBI}=$ traumatic brain injury; UCDBTM = University College Dublin Brain Trauma Model.

SUBMITTED February 25, 2014. ACCEPTED October 17, 2014.

INCLUDE WHEN CITING Published online April 24, 2015; DOI: 10.3171/2014.10.JNS14440.

DISCLOSURE This research was supported by Canadian Institutes of Health Research Strategic Team Grant in Applied Injury Research (TIR-103946), and by funding from the Ontario Neurotrauma Foundation. 
$\mathrm{C}$ ONCUSSION has been defined as short-term cognitive impairment often presenting with symptoms including headaches, dizziness, and nausea after mild head trauma. ${ }^{24}$ While the majority of concussive symptoms resolve, some symptoms persist and can lead to disability and depression, having devastating effects on quality of life..$^{36,37}$ The long-term effects of concussion have been associated with neurological disorders such as chronic traumatic encephalopathy, which is a progressive brain disease characterized by cognitive decline and emotional instability. ${ }^{25,29}$ The combined effects of both shortand long-term outcomes of concussion contribute to the 3.8 million people affected annually by traumatic brain injury (TBI) in the US, costing an estimated $\$ 12$ billion for hospitalization and treatment. ${ }^{7,22}$

The severity of a concussion is typically determined by the number, severity, and duration of presenting symptoms. 3,36,37 Some patients have reported symptoms that resolve within $7-10$ days, ${ }^{23}$ whereas other patients suffer from persistent postconcussive symptoms (PPCS), often having symptoms lasting from months to years.,19,23 Currently, it is not well understood why some patients who sustain head impacts have concussions with transient symptoms while other patients suffer from PPCS.

Concussion can be caused by an impact to the head from a wide array of events including contact sports, motor vehicle accidents, leisure activities, or work accidents. Each event presents unique impact characteristics that define the conditions for the injury. ${ }^{19,36-38}$ The conditions surrounding the head impact play an important role in the outcome of brain injury because this affects how energy from the impact is transmitted to the skull and brain tissues.9,12,26 For example, high-energy impacts involving high-impact velocities and rigid surfaces are more likely to result in skull fractures and subdural hematomas (SDHs) than concussions. ${ }^{43}$ How the head is loaded during an injury event can be described using mechanical characteristics of the impact. These characteristics include details about the impacted/impacting surfaces, the mass and velocity of the two bodies colliding, and the impact location and angle on the head. Conditions describing the impact have been shown to influence head dynamic response and the resulting trauma to the brain.9,12,16,35,41 Dynamic response characteristics describe how the head moves in space after an impact and is measured using linear and rotational acceleration along 3 orthogonal axes of the head. ${ }^{28,33}$ The amount of brain trauma can be described using engineering stress and strain variables as calculated from finite element analysis. ${ }^{4,18,20,40,42}$

Accident reconstruction provides an opportunity for researchers to study the link between measurable parameters of the impact and the resulting injury. 5,6,34 This approach involves obtaining a detailed description of the injury, reconstructing the event under controlled laboratory conditions, using physical or finite element model-head surrogates, and analyzing the results of the reconstruction. ${ }^{28,34}$ Injury reconstruction provides information regarding head dynamic response and brain tissue deformation, and as a result, allows researchers to link metrics such as peak linear and rotational acceleration and brain tissue stress and strain with brain injury outcome..$^{5,6,18,20,34,43,44}$
Past research examining reconstructions of concussive injuries has primarily focused on head impacts resulting in injury and noninjury events. ${ }^{31,44}$ However, reconstructions of more severe TBIs resulting in contusions and SDH have been conducted. ${ }^{6,20,43,44}$ Examining different severities of concussive injuries, such as those presenting with transient symptoms compared with PPCS, has yet to be performed using reconstruction. Moreover, the link between concussive injury severity, as defined by the appearance and persistence of neurocognitive signs and symptoms, and the magnitude of brain trauma sustained has yet to be described. Therefore, the purpose of the present research was to distinguish between groups of concussion with transient symptoms and those with persistent symptoms using head dynamic response and brain tissue stress and strain. While the pathophysiology of concussion is different from SDH injuries, they were included in this analysis for the sole purpose of comparing different types of outcomes using engineering parameters. Characterizing the relationship between engineering parameters and concussion severity will help direct future innovations and interventions to better protect against these injuries.

\section{Methods}

A total of 9 reconstructions were performed. Three patients with transient symptoms (called the "concussion" group), 3 patients with PPCS, and 3 with acute SDH were recruited from sports medicine clinics and hospitals (Table 1). Two cases in the SDH group also presented with contusion, but only the regions of interest for the SDH were used for comparison. This research used a physical reconstruction method combined with finite element analysis to examine the results of each group of brain injury. ${ }^{34,44}$

\section{Patient Groups}

\section{Concussion Group}

The concussion group included cases of patients suffering from concussion and whose symptoms resolved within 10 days. ${ }^{23}$ Inclusion criteria required that patients had clear documentation of the duration of symptoms and details of the injury as noted by a physician. The event description from the medical report was matched to video footage of the injury that confirmed the impact location and surface. All cases were helmeted head impacts against the boards or ice as a result of participation in ice hockey. Injury data were provided by the Mayo Clinic Sports Medicine Center in Rochester, Minnesota. A Sports Medicine Center athletic trainer and physician were present at all home games and identified each concussion case. Players were medically examined in the Sports Medicine Center and their informed consent was obtained in all cases. The medical reports and video footage of the game impacts were made available to guide the reconstructions. Valuable information for reconstruction includes impact location and orientation of the player's head, and the impacting surfaces involved in the collision. To improve the accuracy of the reconstruction, the same helmet model as worn by the player at the time of impact was used for the reconstruction. To determine the impact velocity for each head injury reconstruction, video footage of the event was digitized to calculate inbound velocity of the head prior to impact. 
TABLE 1. Description of head injury events

\begin{tabular}{|c|c|c|c|c|c|}
\hline $\begin{array}{l}\text { Case } \\
\text { No. }\end{array}$ & Injury Group & $\begin{array}{l}\text { Age (yrs), } \\
\text { Sex }\end{array}$ & $\begin{array}{l}\text { Height }(\mathrm{m}) / \\
\text { Weight }(\mathrm{kg})\end{array}$ & Event Description & $\begin{array}{l}\text { Outcome/Symptom } \\
\text { Duration }\end{array}$ \\
\hline 1 & Concussion & $18, M$ & NA & $\begin{array}{l}\text { Skating forwards, tripped \& fell backwards, hit back of helmet on ice. No record of } \\
\text { previous head injury. }\end{array}$ & 8 days \\
\hline 2 & Concussion & $16, \mathrm{M}$ & $1.73 / 74$ & $\begin{array}{l}\text { Attempted to body check, got pulled into the boards \& hit chin. No record of previ- } \\
\text { ous head injury. }\end{array}$ & 9 days \\
\hline 3 & Concussion & $18, M$ & $1.52 / 75$ & $\begin{array}{l}\text { Body checked by another player \& hit It cheek on the boards. Had } 3 \text { previous } \\
\text { concussions. }\end{array}$ & 6 days \\
\hline 4 & PPCS & $59, \mathrm{~F}$ & $1.67 / 95$ & $\begin{array}{l}\text { Walking, slipped backwards on ice \& hit back of head. No record of previous head } \\
\text { injury. }\end{array}$ & $26 \mathrm{mos}$ \\
\hline 5 & PPCS & $52, \mathrm{~F}$ & NA/75 & $\begin{array}{l}\text { Standing on skates and fell backwards on ice \& hit back region of head. No } \\
\text { record of previous head injury. }\end{array}$ & $23 \mathrm{mos}$ \\
\hline 6 & PPCS & $48, M$ & NA & Was in a parking lot \& walked into a street sign. No record of previous head injury. & $28 \mathrm{mos}$ \\
\hline 7 & TBI & $54, \mathrm{~F}$ & NA & $\begin{array}{l}\text { Was playing curling, slipped \& fell backwards, hit back of head. No record of } \\
\text { previous head injury. }\end{array}$ & Contusion, SDH \\
\hline 8 & TBI & $45, M$ & NA & $\begin{array}{l}\text { Standing on wooden dock, slipped \& hit back region of head on dock. No record } \\
\text { of previous head injury. }\end{array}$ & $\mathrm{SDH}$ \\
\hline 9 & TBI & $52, \mathrm{M}$ & NA & $\begin{array}{l}\text { Slipped \& fell on ice-covered pavement \& head on curb. No record of previous } \\
\text { head injury. }\end{array}$ & Contusion, SDH \\
\hline
\end{tabular}

$\mathrm{NA}=$ not available.

PPCS Group

The PPCS group was defined as those with concussion symptoms lasting at least 6 months. ${ }^{23}$ Inclusion criteria required that patients had documentation of the duration of symptoms and details of the impact event from a physician. The 3 cases for PPCS had symptoms that persisted for 23, 26, and 28 months and had not yet resolved (Table 1). These cases were recruited from the Ottawa General Hospital in Ottawa, Canada. Two cases were the result of nonhelmeted falls and 1 case was a nonhelmeted head impact against a steel panel because the subject walked into a street sign (case 6). For Case 6, the impact velocity of $1.5 \mathrm{~m} / \mathrm{sec}$ was taken from the literature for average walking speed. ${ }^{2,10}$ Documented medical reports provided the details for eligibility as well as information regarding head impact conditions used for reconstruction, such as impact location and orientation of the patient's body and head prior to impact.

\section{SDH Group}

Inclusion criteria for the SDH group required that patients presented with SDH without skull fracture and were injured as a result of an uncomplicated fall onto a rigid surface. These cases were the result of nonhelmeted falls onto wood, concrete, or ice and had outcomes of acute SDH alone or acute SDH as well as brain contusions. Patients were recruited from the Centre de Santé et de Services Sociaux (CSSS) Gatineau (Hull site), Canada; St. Michael's Hospital in Toronto, Canada; and Beaumont Hospital in Dublin, Ireland, where care was provided and information for reconstruction was also collected. Similar to the PPCS group, reconstruction parameters were obtained from medical reports and CT scans. The CT scans were used to verify the injury for eligibility in the SDH group and to verify the impact location on the head when superficial bruising or swelling was identified.
Because video footage was not available for the PPCS and SDH groups to estimate impact velocity, the computer simulation software Mathematical Dynamic Models (MADYMO) was used. MADYMO is software that has a database of human body models used to study pedestrian and vehicle accidents (TASS International, 2004). The MADYMO software is used to establish a human body model using information from the medical report, and to simulate the head and body kinematics for each fall incident. ${ }^{5,6,34}$ In a series of uncomplicated fall reconstructions by Doorly and Gilchrist in 2009, the authors reported that a MADYMO-constructed accident resulted in kinematically realistic falls that matched report descriptions and injury outcomes..$^{5}$ In this study, a representative MADYMO (version 7.4; TASS) human body model scaled to the height and weight of each patient was used to estimate the head impact velocity for each injury scenario. The dynamics of each fall were best matched to the description obtained from the medical reports. If skin lacerations or bruises were documented in the report, simulations would include having the model contact the ground with the body part involved. Any effects of these extra motions would be reflected in the final head impact velocity obtained from the simulation. As such, a range of impact velocities was investigated by recreating a number of plausible scenarios for each case to establish low- and high-end impact velocities. Due to the difficulty of obtaining the exact parameters for each reconstruction, this analysis was necessary to capture a range of possible velocities with which the injury may have occurred. The ranges of velocities are presented in Table 2 . The lowest head velocity values were chosen for physical reconstructions and analysis. These were chosen to represent the most conservative velocity associated with the injury event case and to decrease the likelihood of damaging the test equipment, since many of these cases involved unprotected impacts onto rigid surfaces. 
TABLE 2. Reconstruction parameters for each head injury case

\begin{tabular}{cllll}
\hline $\begin{array}{c}\text { Case } \\
\text { No. }\end{array}$ & $\begin{array}{c}\text { Injury } \\
\text { Classification }\end{array}$ & Surface & $\begin{array}{c}\text { Impact Velocity } \\
(\mathrm{m} / \mathrm{sec})\end{array}$ & $\begin{array}{c}\text { Impact } \\
\text { Location }\end{array}$ \\
\hline 1 & Concussion & Ice & 5.9 & Rear \\
\hline 2 & Concussion & Pine wood & 3.6 & Front chin \\
\hline 3 & Concussion & Pine wood & 3.7 & Lt side \\
\hline 4 & PPCS & Concrete & $3.9-4.69-5.2^{*}$ & Rear \\
\hline 5 & PPCS & Ice & $4.1-5.87^{*}$ & Rear \\
\hline 6 & PPCS & Steel & 1.5 & Lt side \\
\hline 7 & SDH & Concrete & $3.7-4.21-5.76^{*}$ & Rear \\
\hline 8 & SDH & Pine wood & $4.8-5.0-6.2^{*}$ & Rear \\
\hline 9 & SDH & Concrete & $3.8-6.0$ & Rear boss \\
\hline
\end{tabular}

* Separate values represent the range of possible velocities with which the injury event occurred.

\section{Laboratory Reconstruction}

Physical Reconstruction

Once the impact variables such as location, velocity, head orientation, and impact surface compliance were calculated using medical report forms, video footage, and MADYMO simulations, these variables were used as input to guide physical reconstruction. Head impact variables for reconstruction are listed in Table 2 for each case.

To reconstruct the head impacts, a 50th percentile adult male Hybrid III head- and neckform (Humanetics ATD) (with mass $6.08 \pm 0.01 \mathrm{~kg}$ ) coupled with a monorail drop rig were used (Fig. 1). A monorail drop rig system was chosen because head impacts were onto a stationary or immovable surface, such as a steel sign or concrete surface, respectively. The monorail drop rig used a sliding carriage situated on a rail to guide a fixed Hybrid III headand neckform during the drop. The Hybrid III headform was equipped with 9 single-axis Endevco accelerometers (model 7264C-2KTZ-2-300) arranged in a 3-2-2-2 array to measure linear and rotational accelerations. ${ }^{30}$ The resultant linear and rotational accelerations were recorded at $20 \mathrm{kHz}$ and were filtered using a low-pass Butterworth filter at $1650 \mathrm{~Hz}$.

\section{University College Dublin Brain Trauma Model}

The acceleration-time histories of the $\mathrm{x}, \mathrm{y}$, and $\mathrm{z}$ axes obtained using the Hybrid III head impacts were used as input into a finite element model of the human brain, the University College Dublin Brain Trauma Model (UCDBTM). This model was developed by Horgan \& Gilchrist $^{14,15}$ and is composed of 26,000 elements comprising the skull, scalp, pia, falx, tentorium, CSF, gray and white matter, cerebellum, and brainstem. A sliding boundary condition between the skull and brain was accomplished by modeling the CSF using solid elements with low-shear moduli. ${ }^{15}$ The brain tissue material properties governing this model are reported in Tables 3 and 4..$^{14,15}$ The UCDBTM was validated by comparing brain model simulation responses against cadaver head impact experiments ${ }^{11,27,39}$ as well as reconstructions of TBIs.,34 Brain tissue deformation measures of maximum principal strain and von Mises stress were used to compare brain injury for

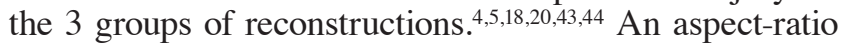

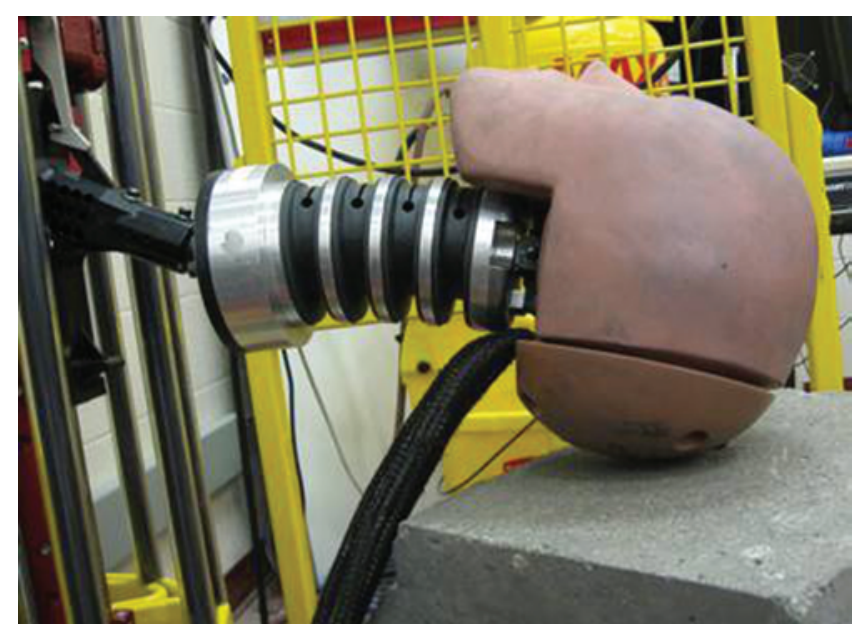

FIG. 1. Hybrid III head- and neckform attached to a monorail drop rig with a concrete impact surface. Figure is available in color online only.

check was performed on all elements of the brain model for each simulated impact to identify potential sources of error due to overly distorted elements. Elements that had aspect ratios exceeding a value of 3 were reviewed; those that changed more than a value of 4 over the course of the simulation were excluded from analysis. This accounted for a total of 167 elements. For the concussion and PPCS cases, the brain tissue deformation results are reported as peak stress or strain in the overall cerebrum of the brain model. However, for the SDH cases, peak stress or strain was determined in the regions of elements that were associated with the area of injury, as indicated by a CT scan. Figure 2 provides an illustration of the brain tissue analysis conducted for SDH cases. A CT scan with an SDH is indicated with a red arrow (Fig. 2 left), and the associated group of elements in the brain finite element model corresponding to the region of injury is shown in red for a top view (Fig. 2 right).

\section{Statistical Analyses}

Due to the small number of samples for each group (n

TABLE 3. Brain tissue characteristics as defined in the UCDBTM

\begin{tabular}{lccl}
\hline \multicolumn{1}{c}{ Material } & $\begin{array}{c}\text { Young's Modulus } \\
(\mathrm{MPa})^{*}\end{array}$ & $\begin{array}{c}\text { Density } \\
\left(\mathrm{kg} / \mathrm{m}^{3}\right)\end{array}$ & $\begin{array}{c}\text { Poisson's } \\
\text { Ratio } \dagger\end{array}$ \\
\hline Scalp & 16.7 & 1000 & 0.42 \\
\hline Trabecular bone & 1000 & 1300 & 0.24 \\
\hline Cortical bone & 15,000 & 2000 & 0.22 \\
\hline Pia & 11.5 & 1130 & 0.45 \\
\hline Dura & 31.5 & 1130 & 0.45 \\
\hline Falx/tentorium & 31.5 & 1140 & 0.45 \\
\hline CSF & - & 1000 & 0.5 \\
\hline White matter & Hyperelastic & 1060 & 0.499997 \\
\hline Gray matter & Hyperelastic & 1060 & 0.499998 \\
\hline
\end{tabular}

* Young's Modulus $=$ measure of material stiffness characterized by the ratio of stress to strain.

$\dagger$ Poisson's Ratio $=$ measure of the deformability of a material to an external force or load; calculated by taking the ratio of the change in length of a material to its change in thickness. 
TABLE 4. Brain tissue material properties for the UCDBTM

\begin{tabular}{|c|c|c|c|c|}
\hline \multirow[b]{2}{*}{ Material } & \multicolumn{2}{|c|}{ Shear Modulus $(\mathrm{kPa})^{*}$} & \multirow[b]{2}{*}{$\begin{array}{l}\text { Bulk Modulus } \\
\qquad(\mathrm{GPa}) \dagger\end{array}$} & \multirow[b]{2}{*}{$\begin{array}{l}\text { Decay Constant } \\
\qquad\left(\mathrm{sec}^{-1}\right) \ddagger\end{array}$} \\
\hline & $\mathrm{G}_{0}$ & $\mathrm{G}_{\infty}$ & & \\
\hline Cerebellum & 10 & 2.0 & 2.19 & 80 \\
\hline Gray matter & 10 & 2.0 & 2.19 & 80 \\
\hline White matter & 12.5 & 2.5 & 2.19 & 80 \\
\hline Brainstem & 22.5 & 4.5 & 2.19 & 80 \\
\hline
\end{tabular}

\footnotetext{
* Shear Modulus $=$ the viscoelastic (time-dependent) nature of a material in response to loading. Shear modulus is represented by 2 constants and measured in Pascals. $G_{0}$ characterizes the stored energy or the elastic portion of the material. $G_{\infty}$ characterizes the amount of energy lost or dissipated as heat and is also known as the viscous portion.

$\dagger$ Bulk Modulus $=$ a measure of the compressibility of a material in Pascals

$\ddagger$ Decay Constant $=$ a rate constant that defines the diminishing effect of a constant load.
}

= 3), a nonparametric Kruskal-Wallis test was used to test for significant differences among the 3 injuries (concussion, PPCS, and SDH) for each dependent variable of interest (linear and rotational acceleration, maximum principal strain, and von Mises stress). Post hoc comparisons were completed using the Tukey method with the significance level set to $\mathrm{p}<0.05$.

\section{Results}

A description of each injury event and the parameters used for each case are presented in Tables 1 and 2, respectively. The dynamic response and brain tissue deformation results for each case are presented in Table 5 along with the mean and standard deviation for each injury group. Results of the Kruskall-Wallis test showed a significant difference between injury groups for peak resultant linear acceleration $\left(\chi_{(\mathrm{df}=2)}^{2}=16.222, \mathrm{p}<0.001\right)$ with mean rank scores for concussion, PPCS, and SDH of 7.67, 12.00, and 22.33, respectively. Additionally, significant differences were found for peak resultant rotational acceleration $\left(\chi_{(\mathrm{df}=2)}^{2}=14.000\right.$, $\mathrm{p}=0.001$ ), with mean rank scores of 7.00 for concussion, 14.00 for PPCS, and 21.00 for SDH. No significant differences were found for either brain tissue measures of maximum principal strain $\left(\chi_{(\mathrm{df}=2)}^{2}=3.109, \mathrm{p}=0.211\right)$ or von Mises stress $\left(\chi_{(\mathrm{df}=2)}^{2}=5.001, \mathrm{p}=0.082\right)$. The Tukey post
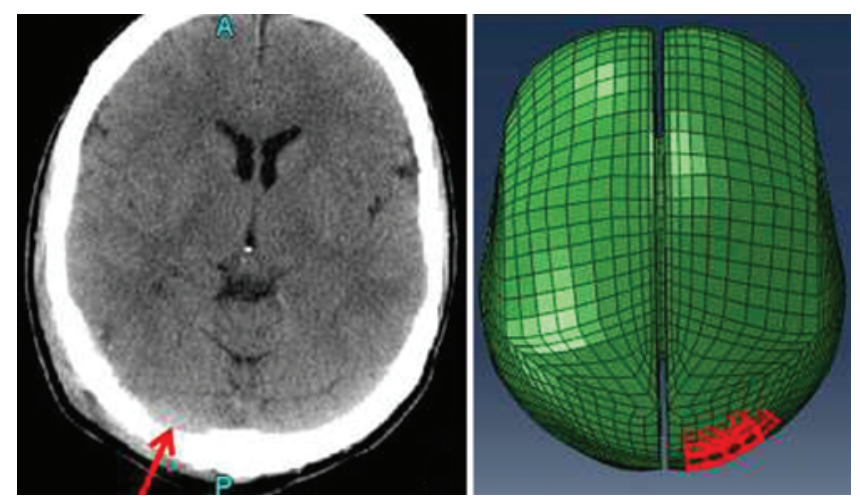

FIG. 2. The subset of finite elements (red area) in the UCDBTM (right) that are associated with the region of SDH (red arrow) on a CT scan (left). Figure is available in color online only. hoc analysis showed that the SDH group had statistically higher linear $(316 \mathrm{~g})$ and rotational acceleration $(23,181$ $\mathrm{rad} / \mathrm{sec}^{2}$ ) responses than the concussion group (149 $\mathrm{g}$ and $8111 \mathrm{rad} / \mathrm{sec}^{2}$, respectively; $\mathrm{p}<0.05$ ).

\section{Discussion}

This study compared head dynamic and brain tissue responses obtained from reconstructions of 2 different severities of concussion, those resulting in transient and persistent symptoms. A group of traumatic SDH injuries was also included in the analysis for the purpose of comparing concussion with more severe injury outcomes. On average, head dynamic response values were lower for less severe transient concussion and higher for SDH injuries. This was observed for both linear and rotational acceleration. The average dynamic response for persistent concussion (PPCS) had values that were between the other 2 injury groups; however, these differences were not significant. Individual examination of the case results for PPCS showed head dynamic and brain tissue response values that overlap with lower-severity concussion as well as the SDH injuries. While this observation may lead to some speculation about the magnitude of impacts resulting in the severity of concussive injuries, due to the low number of cases for each group it is difficult to generalize these findings.

In the past, researchers have investigated the individual roles of linear and rotational acceleration on brain trauma outcome. Linear acceleration was associated with focal injuries such as hematomas, whereas rotational acceleration is characteristic of diffuse injuries such as concussion. ${ }^{8,9}$ The importance of rotation as the primary mechanism for diffuse brain injuries was originally hypothesized by Holbourn, who used a gelatin model of the brain to demonstrate the ease of deformation of brain tissue to shear strain as compared with a compressive strain. ${ }^{13}$ This current study does not support or refute these findings, as the limited number of cases does not allow for any separation of concussion severity with types of head acceleration. As more reconstructions of concussive injuries are conducted, the importance of rotational acceleration for human head injury will be better understood.

Past research using finite element analysis has suggested that tissue stress and strain, used to describe brain tissue deformation, may be better variables to predict severity of injury. ${ }^{18,20,40}$ It is interesting to find that brain tissue response measures were not found to be significantly different for injury outcomes. On average, concussion and PPCS had similar values, while SDH injuries had lower values than both groups. One reason that may explain these findings is that finite element analysis of the SDH injuries examined stress and strain values in a specific group of elements in the brain model that corresponded to the region of bleeding on the CT scan. As a result, these brain tissue values may not be the highest values if the entire cerebrum was considered. More importantly, SDH injuries are primarily lesions to vascular tissue; therefore, they may not necessarily be associated with stresses or strains on the brain.

In the past, high-severity TBIs resulting in lesions were compared with lower-severity impacts resulting in con- 


\begin{abstract}
TABLE 5. Individual case data, including mean and 1 standard deviation, of peak resultant linear $(\mathrm{g})$ and rotational acceleration $\left(\mathrm{rad} / \mathrm{sec}^{2}\right)$, and peak maximum principal strain and von Mises stress $(\mathrm{kPa})$ for head injuries resulting in concussion, PPCS, and SDH
\end{abstract}

\begin{tabular}{clcccc}
\hline $\begin{array}{c}\text { Case } \\
\text { No. }\end{array}$ & Injury Group & $\begin{array}{c}\text { Peak Linear Acceleration } \\
(g)^{*}\end{array}$ & $\begin{array}{c}\text { Peak Rotational Acceleration } \\
\left(\mathrm{rad} / \mathrm{sec}^{2}\right)\end{array}$ & $\begin{array}{c}\text { Peak Max Principal } \\
\text { Strain† }\end{array}$ & $\begin{array}{c}\text { Peak von Mises Stress } \\
(\mathrm{kPa}) \ddagger\end{array}$ \\
\hline 1 & Concussion & 187 & 11,700 & 0.608 & 20.6 \\
\hline 2 & Concussion & 209 & 9767 & 0.487 & 17.8 \\
\hline 3 & Concussion & 52 & 2865 & 0.187 & 6.2 \\
\hline & Mean (SD) & $149(74)$ & $8111(4056)$ & $0.427(0.2)$ & $14.9(6.6)$ \\
\hline 4 & PPCS & 266 & 23,211 & 0.594 & 19.2 \\
\hline 5 & PPCS & 227 & 21,323 & 0.577 & 19.5 \\
\hline 6 & PPCS & 53 & 4847 & 0.207 & 7.4 \\
\hline & Mean (SD) & $182(98)$ & $16,460(8765)$ & $0.459(0.2)$ & $15.4(6.0)$ \\
\hline 7 & SDH & 268 & 14,044 & 0.228 & 7.3 \\
\hline 8 & SDH & 414 & 30,799 & 0.305 & 10.4 \\
\hline 9 & SDH & 266 & 24,700 & 0.232 & 6.9 \\
\hline & Mean (SD) & $316(74)$ & $23,181(7354)$ & $0.255(0.043)$ & $8.2(1.7)$ \\
\hline
\end{tabular}

* Linear Acceleration $=$ translational motion and is measured in $g$ as a factor of gravitational acceleration $\left(9.81 \mathrm{~m} / \mathrm{sec}^{2}\right)$.

† Maximum Principal Strain = proportional to the largest magnitude of strain in the $x, y$, or $z$ axes of a material.

$\ddagger$ von Mises Stress = the 3D state of stress in a material represented using a single value that summarizes the stress in the $x, y$, and $z$ axes.

cussion or no concussion..$^{5,20,32,44}$ For these studies, peak variables of maximum principal strain and von Mises stress have been identified as possible relevant variables to describe the relative risk of injury. ${ }^{20,43,44}$ Because SDHs occur as a result of tearing of bridging veins, it might be more revealing to examine the amount of stress and strain experienced by vascular tissues for these types of injuries. Furthermore, to distinguish the subtle differences between concussion and PPCS, different brain deformation variables may be more effective in characterizing the injury. Lamy et al. ${ }^{21}$ conducted experimental research investigating the effect of rotational head injury on the duration of loss of consciousness and level of histological evidence on rat brains. These authors modeled the responses using finite element analysis and suggested that a von Mises stress-time metric may be better associated with the severity of injury as demonstrated by histological data and duration of loss of consciousness than peak von Mises stress alone. This research only investigated the role of rotational acceleration and was specific to rat models of head injury; however, it suggests that other parameters may be necessary for describing severity of concussion.

While all injury reconstructions presented in this study were from direct blows to the head, other confounding factors such as patient and event characteristics are likely to have influenced the results. All cases of concussion with transient symptoms were male adolescents (mean age 17 years) who were helmeted at the time of injury, and playing competitive hockey. Patients presenting with severe PPCS and SDH were middle-aged adults (mean age 52 years) who were not helmeted at the time of impact. There may have been a selection bias due to the difficulty of obtaining reconstructable injury events for each group. A large number of concussions go unreported each year, especially if they are minor and do not require medical attention. Additionally, clear documentation of the cessation of concussive symptoms is also difficult to obtain, which is one reason why the transient concussion cases were obtained from an organized sports team. The hockey team had the resources available to quickly diagnose and follow up with each injured player. Consequently, the more severe cases of injuries were recruited from hospitals and were composed of much older adults who required immediate medical attention. An advantage of this hospitalized population is clear documentation of the duration of symptoms and injury outcomes.

While it is understood that these patient-specific factors and injury event characteristics influence the results, ${ }^{17}$ the main objective of this study was to demonstrate how biomechanical measures of brain injury compare for different severities of concussion in comparison with more severe SDH injury outcomes. The initial findings from this study support the notion that head acceleration variables are able to distinguish between transient concussions and more severe SDH; however, these findings merit further research on improved injury measures that are sensitive to the spectrum of concussion severity. As more reconstruction research on concussion begins to fill the gap between the presence of concussive injury and SDH, future research examining the spectrum of concussion should also include additional engineering parameters to describe brain injury.

Challenges associated with injury reconstruction include sample size and limited availability of video footage for 6 of the 9 cases. The difficulty in obtaining cases that could be accurately reconstructed limited the number of samples to specific subject pools such as young ice hockey players and middle-aged adults who were injured as a result of a fall. Future work would benefit from increasing the sample sizes for each injury group as well as diversifying the types of events that cause concussion.

While eyewitness and patient accounts of accidents are a major limitation to reconstruction, MADYMO currently provides a reasonable method to estimate head impact velocities for fall-type accidents. Unfortunately, victims with 
serious injuries are rarely filmed or instrumented to measure the kinematics and as a result, MADYMO simulation of the PPCS and SDH cases was necessary to determine head impact velocity. The human-body surrogates used in the physical reconstruction process are idealized representations of the complex geometries and do not necessarily account for the more compliant nature of soft tissues. The Hybrid III headform used to collect the head dynamic response data was a rigid steel headform covered with a vinyl layer to simulate the soft tissues of the scalp. Although this headform is commonly used in head-impact research, it is not an exact reflection of the characteristics of a human head. Similarly, the MADYMO human-body models are composed of a series of idealized ellipsoids used to represent the human body. The geometry of the finite element model is also a generalized model that does not account for the individual differences among the subjects. The intracranial response variables examined in this research were specific to a single head-impact event reconstructed from medical reports and do not take into account the state of brain deformation as a result of accumulated head injuries such as those with multiple concussions. In addition, the material properties used to define the finite element model were based on both cadaver and animal studies and may not be reflective of the response of live human brain tissue to impact.

\section{Conclusions}

This study demonstrates a positive relationship between an increase in head dynamic response and the risk for more serious brain injury when comparing transient concussion (low severity) and traumatic SDH injuries. This type of relationship was not found for brain tissue stress and strain results derived by finite element analysis. More importantly, neither head dynamic variables nor brain tissue response variables were able to distinguish between transient and persistent concussions. Increasing the number of concussive injuries is important to identify appropriate variables that may be more effective in characterizing the spectrum of concussion. A more intimate understanding of the relationship between dynamic response variables of the head and risk of brain trauma is critical for developing strategies for injury prevention.

\section{Acknowledgments}

We would like to thank the Mayo Clinic Sports Medicine Center for providing the data for the ice hockey concussions, the Ottawa Hospital for the postconcussion syndrome data, and the Centre de Santé et de Services Sociaux (CSSS) Gatineau (Hull site) for the subdural hematoma/contusion reconstruction data.

\section{References}

1. Alves W, Macciocchi SN, Barth JT: Postconcussive symptoms after uncomplicated mild head injury. J Head Trauma Rehabil 8:48-59, 1993

2. Bohannon RW: Comfortable and maximum walking speed of adults aged 20-79 years: reference values and determinants. Age Ageing 26:15-19, 1997

3. Cantu RC: Cerebral concussion in sport. Management and prevention. Sports Med 14:64-74, 1992

4. Deck C, Willinger R: Improved head injury criteria based on head FE model. Int J Crashworthiness 13:667-678, 2008
5. Doorly MC, Gilchrist MD: Three-dimensional multibody dynamics analysis of accidental falls resulting in traumatic brain injury. Int J Crashworthiness 14:503-509, 2009

6. Doorly MC, Gilchrist MD: The use of accident reconstruction for the analysis of traumatic brain injury due to head impacts arising from falls. Comput Methods Biomech Biomed Engin 9:371-377, 2006

7. Finkelstein EA, Corso PS, Miller TR: The Incidence and Economic Burden of Injuries in the United States. New York: Oxford University Press, 2006

8. Gennarelli TA, Ommaya AK, Thibault LE: Comparison of translational and rotational head motions in experimental cerebral concussion, in Proceedings of the 15th Stapp Car Crash Conference. Warredale, PA: Society of Automotive Engineers, 1971, pp 797-803

9. Gennarelli TA, Thibault LE, Adams JH, Graham DI, Thompson CJ, Marcincin RP: Diffuse axonal injury and traumatic coma in the primate. Ann Neurol 12:564-574, 1982

10. Gilchrist MD, Keenan S, Curtis M, Cassidy M, Byrne G, Destrade M: Measuring knife stab penetration into skin simulant using a novel biaxial tension device. Forensic Sci Int 177:52-65, 2008

11. Hardy WN, Foster CD, Mason MJ, Yang KH, King AI, Tashman S: Investigation of head injury mechanisms using neutral density technology and high-speed biplanar X-ray. Stapp Car Crash J 45:337-368, 2001

12. Hodgson VR, Thomas LM, Khalil TB: The role of impact location in reversible cerebral concussion, in Proceedings of the 27th Stapp Car Crash Conference. Warredale, PA: Society of Automotive Engineers, 1983, pp 225-240

13. Holbourn AHS: The mechanics of brain injuries. Br Med Bull 3:147-149, 1945

14. Horgan TJ, Gilchrist MD: The creation of three-dimensional finite element models for simulating head impact biomechanics. Int J Crashworthiness 8:353-366, 2003

15. Horgan TJ, Gilchrist MD: Influence of FE model variability in predicting brain motion and intracranial pressure changes in head impact simulations. Int J Crashworthiness 9:401418, 2004

16. Karton C, Post A, Hoshizaki B, Gilchrist MD: The assessment of inbound mass variation on the distribution of brain tissue deformation, in Childs PRN, Bull A, Ghajari M (eds): 1st International Conference on Helmet Performance and Design. London: DEG Imperial College London, 2013, pp A3-1 (Abstract)

17. Kendall M, Post A, Rousseau P, Oeur A, Gilchrist MD, Hoshizaki B: A comparison of dynamic impact response and brain deformation metrics within the cerebrum of head impact reconstructions representing three mechanisms of head injury in ice hockey, in 2012 International Research Council on the Biomechanics of Impact (IRCOBI) Conference. 12-14 September 2012-Dublin (Ireland). (http:// www.ircobi.org/downloads/irc12/pdf_files/53.pdf) [Accessed March 10, 2015]

18. King AI, Yang KH, Zhang L, Hardy W, Viano DC: Is head injury caused by linear or angular acceleration? Snell Memorial Foundation. (snellfoundation.net/docs/articles/hic/ King_IRCOBI_2003.pdf) [Accessed March 8, 2015]

19. King NS, Kirwilliam S: Permanent post-concussion symptoms after mild head injury. Brain Inj 25:462-470, 2011

20. Kleiven S: Predictors for traumatic brain injuries evaluated through accident reconstructions. Stapp Car Crash J 51:81114,2007

21. Lamy M, Baumgartner D, Willinger R, Yoganandan N, Stemper BD: Study of mild traumatic brain injuries using experiments and finite element modeling. Ann Adv Automat Med 55:125-135, 2011

22. Langlois JA, Rutland-Brown W, Wald MM: The epidemiology and impact of traumatic brain injury: a brief overview. J Head Trauma Rehabil 21:375-378, 2006 
23. Marshall S, Bayley M, McCullagh S, Velikonja D, Berrigan L: Clinical practice guidelines for mild traumatic brain injury and persistent symptoms. Can Fam Physician 58:257267,2012

24. McCrory P, Meeuwisse WH, Aubry M, Cantu B, Dvorák J, Echemendia RJ, et al: Consensus statement on concussion in sport: the 4th International Conference on Concussion in Sport held in Zurich, November 2012. Br J Sports Med 47:250-258, 2013

25. McKee AC, Cantu RC, Nowinski CJ, Hedley-Whyte ET, Gavett $\mathrm{BE}$, Budson $\mathrm{AE}$, et al: Chronic traumatic encephalopathy in athletes: progressive tauopathy after repetitive head injury. J Neuropathol Exp Neurol 68:709-735, 2009

26. Meaney DF, Smith DH: Biomechanics of concussion. Clin Sports Med 30:19-31, vii, 2011

27. Nahum AM, Smith R, Ward CC: Intracranial pressure dynamics during head impact, in 21st Stapp Car Crash Conference Proceedings. Warrendale, PA: Society of Automotive Engineers, 1977, pp 303-335

28. O’Riordain K, Thomas PM, Phillips JP, Gilchrist MD: Reconstruction of real world head injury accidents resulting from falls using multibody dynamics. Clin Biomech (Bristol, Avon) 18:590-600, 2003

29. Omalu BI, Bailes J, Hammers JL, Fitzsimmons RP: Chronic traumatic encephalopathy, suicides and parasuicides in professional American athletes: the role of the forensic pathologist. Am J Forensic Med Pathol 31:130-132, 2010

30. Padgaonkar AJ, Krieger KW, King AI: Measurement of angular acceleration of a rigid body using linear accelerometers. J Appl Mech 42:552-556, 1975

31. Pellman EJ, Viano DC, Tucker AM, Casson IR, Waeckerle JF: Concussion in professional football: reconstruction of game impacts and injuries. Neurosurgery 53:799-814, 2003

32. Post A: The Influence of Dynamic Response Characteristics on Traumatic Brain Injury [dissertation]. Ottawa, Canada: University of Ottawa, 2013

33. Post A, Hoshizaki B, Gilchrist MD: Finite element analysis of the effect of loading curve shape on brain injury predictors. J Biomech 45:679-683, 2012

34. Post A, Hoshizaki TB, Gilchrist M, Brien S: Analysis of the influence of independent variables used for reconstruction of a traumatic brain injury incident. Proc Inst Mech Eng Part P J Sports Eng Technol 226:290-298, 2012

35. Post A, Oeur A, Hoshizaki B, Gilchrist MD: Examination of the relationship between peak linear and angular accelerations to brain deformation metrics in hockey helmet impacts. Comput Methods Biomech Biomed Engin 16:511-519, 2013

36. Rimel RW, Giordani B, Barth JT, Boll TJ, Jane JA: Disability caused by minor head injury. Neurosurgery 9:221-228, 1981
37. Rimel RW, Giordani B, Barth JT, Jane JA: Moderate head injury: completing the clinical spectrum of brain trauma. Neurosurgery 11:344-351, 1982

38. Tator C: Sport concussion education and prevention. J Clin Sport Psychol 6:293-301, 2012

39. Trosseille X, Tarriére C, Lavaste F, Guillon F, Domont A: Development of a F.E.M. of the human head according to a specific test protocol. SAE International. (http://papers.sae. org/922527/) [Accessed March 8, 2015]

40. Ueno K, Melvin JW, Li L, Lighthall JW: Development of tissue level brain injury criteria by finite element analysis. J Neurotrauma 12:695-706, 1995

41. Walsh ES, Rousseau P, Hoshizaki TB: The influence of impact location and angle on the dynamic impact response of a Hybrid III headform. Sports Eng 13:135-143, 2011

42. Ward C: Finite element models of the head and their use in brain injury research. SAE International. (http://papers.sae. org/821154/) [Accessed March 8, 2015]

43. Willinger R, Baumgartner D: Human head tolerance limits to specific injury mechanisms. Int J Crashworthiness 8:605617, 2003

44. Zhang L, Yang KH, King AI: A proposed injury threshold for mild traumatic brain injury. J Biomech Eng 126:226236, 2004

\section{Author Contributions}

Conception and design: Oeur, Hoshizaki. Acquisition of data: Oeur, Karton, Post, Rousseau, Marshall, Brien, Smith, Cusimano, Gilchrist. Analysis and interpretation of data: Oeur, Hoshizaki, Gilchrist. Drafting the article: Oeur, Hoshizaki. Critically revising the article: all authors. Reviewed submitted version of manuscript: Oeur, Post, Hoshizaki, Gilchrist. Approved the final version of the manuscript on behalf of all authors: Oeur. Statistical analysis: Oeur. Administrative/technical/material support: Hoshizaki. Study supervision: Hoshizaki.

\section{Supplemental Information \\ Previous Presentation}

Portions of this work were presented in podium form at the Helmet Performance and Design Conference in London, England, on February 15, 2013.

\section{Correspondence}

R. Anna Oeur, Neurotrauma Impact Science Laboratory, University of Ottawa, 200 Lees Ave., A-106, Ottawa, ON K1S 5S9, Canada.email: anna.oeur@uottawa.ca. 